\title{
Histological types of polyps in large intestine biopsies; a single center experience
}

\author{
Parisa Masoum Zadeh ${ }^{\mathbb{D}}$, Sara Ghorbani ${ }^{\circledR}$, Maryam Derakhshan* ${ }^{\mathbb{D}}$ \\ Department of Pathology, Isfahan University of Medical Sciences, Isfahan, Iran
}

Correspondence to:

Maryam Derakhshan, Email: mderakhshan58@yahoo.com

Received: 19 August 2020 Accepted: 2 November 2020 ePublished: 27 November 2020

Keywords: Polyps, Large intestine, Histopathology

Citation: Masoum
Zadeh P, Ghorbani
S, Derakhshan M.
Histological types of
polyps in large intestine
biopsies; a single center
experience. J Prev
Epidemiol. 2020;5(1):e18.
doi: $10.34172 /$
jpe.2020.18.

\begin{abstract}
Introduction: Large intestine cancer is considered as one of the prevalent cancers among societies. Histological studies have shown that cancers in large intestine often originate from polyps from internal layer of the intestinal epithelial tissue.

Objectives: The aim of this study was to investigate the types of polyps in large intestine biopsies in patients referring to Al-Zahra hospital in Iran.

Patients and Methods: This is a cross-sectional study conducted on patients undergoing colonoscopy in 2014-2019. Characteristics of polyps were noted based on reports of colonoscopy and pathology. Results: In this study, 372 biopsies from patients aged between 10-96 years were analyzed. No significant difference was observed between two genders regarding location, size, histology, and morphology of polyps $(P>0.05)$. Adenomatous epithelial polyps are the most common types in all ages). Further analysis showed that most of the discovered polyps $(23.3 \%)$ were in transverse colon.

Conclusion: Adenomatous epithelial polyps are more frequent in patients because most of the discovered polyps were in transverse colon and most of them were adenomatous epithelial. These data were in line with the most of previous studies; however some paradoxical results were reported. More studies on larger populations should be performed.
\end{abstract}

Introduction

Large intestine cancer is accounted as one of the prevalent cancers among societies with the same distribution rates among males and females (1,2). Epidemiologic studies have indicated that large intestine cancer is most prevalent in eastern European and Asian countries and the least prevalence rate has been reported in African and South American countries $(3,4)$. Overall, the large intestine cancer is the second most prevalent cancer among women and the third most prevalent among men $(5,6)$. Changes in lifestyle and increased life-expectancy have caused an increasing prevalence rate among both developed and developing countries (6). Studies have indicated that both environmental and genetic factors have pivotal roles in pathogenesis of the disease (7).

Histological studies have shown that cancers in the large intestine often originate from polyps in the intestine. The origin of the polyps is internal layer of the intestine epithelial tissue (8). Studies indicated that genetic changes in some epithelial cells could lead to collection of immature and mutant

\section{Key point}

In our study, from 372 biopsies in patients aged 10-96 years who undergoing colonoscopy in 20142019, we found that adenomatous epithelial polyps are more frequent in patients.

cells presenting as polyps which could have mild or no symptoms (8). Polyps could be observed in different areas of the intestine but they are mostly probable to be observed in the large intestine. Most of these polyps are benign, however almost all of them contain some degrees of dysplasia and have the potential of turning to intestinal malignancy. Tubular, villous and tubular-villous are three main types of adenomatous polyps based on histological studies (11). Almost 68$80 \%$ of the diagnosed polyps are known to be adenomatous polyps. Histopathological characteristics of polyps are pivotal factors for prediction of malignancy possibilities in these patients. Increase in diameter of polyps, increased dysplasia and associated clinical symptoms are known to increase the risks of malignancy in patients $(12,13)$. 
Colonoscopy is an important diagnostic method for problems in the large intestine. Colonoscopy is performed for screening the patients suspicious to large intestine cancer or for evaluation of special conditions including intestinal polyposis $(14,15)$. Intestine biopsy is also performed by the means of colonoscopy in patients (16).

\section{Objectives}

Results of biopsies are important in patients because as spoken above, histopathological characteristics of polyps could predict the risks of malignancies. Regarding the importance of large intestine polyps and their histopathological details and regarding the high prevalence of intestinal cancer among populations, here we aimed to evaluate the types of polyps in large intestine biopsies in patients referring to Al-Zahra hospital in Iran.

\section{Patients and Methods}

\section{Study design}

This is a cross-sectional study performed in 2020 in Isfahan. This study was performed on the documents of patients referring to Al-zahra hospital in Isfahan and undergoing colonoscopy in 2014-2019. The inclusion criteria were; presence of full total colonoscopy report in the documents of patients and also reports of polyps and full pathology report of polyp biopsies in medical record of patients. The exclusion criteria were; having history of cancer, having history of polyposis or positive family history of polyposis, reports of polyps in colonoscopy but no evidence of polyps in pathology studies, tumor lesions presented as polyp forms and lack of sufficient data in medical records.

We included all patients who were referred to our medical center for screening colonoscopy based on inclusion and exclusion criteria. Information regarding: age, gender and time of colonoscopy. Characteristics of polyps were also noted based on reports of colonoscopy and pathology. Additionally, number of polyps in patients were noted.

Location of polyps was divided into six categories; rectum, sigmoid, descending colon, transverse colon, ascending colon and cecum. Polyps were also classified based on their size into six groups; lower than $5 \mathrm{~mm}$, 6-10 mm, 11-20 mm, 21-50 mm, larger than $50 \mathrm{~mm}$ and unidentified. Polyps were also classified into four groups based on their histologic details; epithelial (containing hyperplastic, adenomatous, juvenile and mixed), inflammatory [in framework of inflammatory bowel disease (IBD) or prolapse or unknown], hamartoma (Peutz-Jeghers syndrome) and mesenchymal (divided into three groups of vascular, lymphoid and fibroid). In cases with lack of these data, pathology reports and also biopsy samples were re-reviewed.

\section{Ethical issues}

The research followed the tenets of the Declaration of
Helsinki. The Ethics Committee of Isfahan University of Medical Sciences approved this study. The institutional ethical committee at Isfahan University of Medical Sciences approved all study protocols (IR.MUI.REC.1398.431). Accordingly, written informed consent was taken from all participants before any intervention. This study was extracted from M.D thesis of Parisa MasoumZadeh at this university (Thesis\#398557).

\section{Data analysis}

Data were collected and analyzed using SPSS software version 23 and chi-square and Mann-Whitney $U$ analysis tests. $P$ value less than 0.05 was considered as the significance threshold.

\section{Results}

In this study, 372 biopsies from patients aged 10-96 years were evaluated. The mean age of patients was $58.28 \pm 14.3$ years. Our primary analysis showed that $62.4 \%$ of the study populations were male and $37.6 \%$ were female.

Histologic and morphologic details of polyps were compared between males and females. These data showed no significant differences between two genders regarding location, size, histology and morphology of polyps $(P>$ 0.05; Table 1).

Data were analyzed based on age groups (older than 58 years and younger than 58 years). Adenomatous epithelial polyps are the most common types in all ages; Table 2).

Further analysis showed that most of the discovered polyps $(23.3 \%)$ were in ation of polyps were divided int transverse colon. Of 87 discovered polyps in ation of polyps were divided int transverse colon, $80.5 \%$ were adenomatous epithelial polyps. Data regarding the characteristics of polyps based on their location are summarized in Table 3 and Figures 1 and 2.

\section{Discussion}

Here in the present study, we evaluated the distribution of histologic types of polyps in large intestine biopsies among 372 biopsies. Our data showed no significant differences between two genders regarding location, size, histology and morphology of polyps. Our data shows that adenomatous epithelial polyps are the most common types in all ages). Further analysis showed that most of the discovered polyps were in transverse colon and most of them were adenomatous epithelial. Previous studies have evaluated different aspects of large intestine biopsies in patients.

Most of the previous studies have emphasized on different characteristics of biopsies in a particular location in patients and very few studies have investigated different histopathological details of large intestine biopsies. In a study by Galamb et al, samples of colon biopsies were evaluated and gene expression analysis was performed. They reported that adenomatous epithelial polyps were most frequent among patients and using routine 
Table 1. Histologic and morphologic details of polyps based on gender

\begin{tabular}{|c|c|c|c|c|c|c|c|}
\hline \multirow{2}{*}{ Variable } & & \multicolumn{2}{|c|}{ Female $(n=140)$} & \multicolumn{2}{|c|}{ Male $(n=232)$} & \multirow{2}{*}{ Analysis test } & \multirow{2}{*}{$P$ value } \\
\hline & & No. & $\%$ & No. & $\%$ & & \\
\hline \multirow{6}{*}{$\begin{array}{l}\text { Location of } \\
\text { polyps }\end{array}$} & Ascending colon & 28 & 20 & 46 & 19.8 & \multirow{6}{*}{ Chi-square } & \multirow{6}{*}{0.91} \\
\hline & Descending colon & 29 & 20.7 & 50 & 21.6 & & \\
\hline & Transverse colon & 31 & 22.1 & 56 & 24.1 & & \\
\hline & Rectum & 16 & 11.4 & 27 & 27 & & \\
\hline & Cecum & 10 & 7.1 & 20 & 20 & & \\
\hline & Sigmoid & 26 & 18.6 & 33 & 33 & & \\
\hline \multirow{5}{*}{ Size of polyps } & Less than 5 & 66 & 47.1 & 112 & 48.3 & \multirow{5}{*}{ Chi-square } & \multirow{5}{*}{0.44} \\
\hline & $6-10$ & 52 & 37.1 & 70 & 30.2 & & \\
\hline & $11-20$ & 17 & 12.1 & 36 & 15.5 & & \\
\hline & $21-50$ & 5 & 3.6 & 12 & 5.2 & & \\
\hline & More than 50 & 0 & 0 & 2 & 0.9 & & \\
\hline \multirow{8}{*}{$\begin{array}{l}\text { Histology of } \\
\text { polyps }\end{array}$} & Epithelial (adenomatous) & 111 & 79.3 & 189 & 81.5 & \multirow{8}{*}{ Chi-square } & \multirow{8}{*}{0.37} \\
\hline & Epithelial (hyperplastic) & 18 & 12.9 & 18 & 7.8 & & \\
\hline & Hamartoma (Peutz-Jeghers) & 0 & 0 & 4 & 1.7 & & \\
\hline & Epithelial (juvenile) & 1 & 2.2 & 5 & 0.7 & & \\
\hline & Epithelial (mixed) & 0 & 0 & 1 & 0.4 & & \\
\hline & Inflammatory (IBD) & 6 & 4.3 & 7 & 3 & & \\
\hline & Inflammatory (unknown) & 4 & 3 & 7 & 2.9 & & \\
\hline & Vascular (mesenchymal) & 0 & 0 & 1 & 0.4 & & \\
\hline \multirow{2}{*}{$\begin{array}{l}\text { Morphology of } \\
\text { polyp }\end{array}$} & Sessile & 132 & 94.3 & 212 & 91.8 & \multirow{2}{*}{ Chi-square } & \multirow{2}{*}{0.36} \\
\hline & Pedunculate & 8 & 5.7 & 19 & 8.2 & & \\
\hline \multicolumn{2}{|c|}{ Age (mean \pm SD) (years) } & \multicolumn{2}{|c|}{$54.24 \pm 14.54$} & \multicolumn{2}{|c|}{$58.91 \pm 14.14$} & Mann-Whitney U & 0.22 \\
\hline
\end{tabular}

Table 2. Histologic and morphologic details of polyps based on age

\begin{tabular}{|c|c|c|c|c|c|c|c|}
\hline \multirow{2}{*}{ Variables } & & \multicolumn{2}{|c|}{$<58$ years $(n=175)$} & \multicolumn{2}{|c|}{$>58$ years $(n=196)$} & \multirow{2}{*}{ Analysis test } & \multirow{2}{*}{$P$ value } \\
\hline & & $\mathbf{N}$ & $\%$ & $N$ & $\%$ & & \\
\hline \multirow{6}{*}{ Location of polyps } & Ascending colon & 33 & 18.8 & 41 & 20.9 & \multirow{6}{*}{ Chi-Square } & \multirow{6}{*}{0.34} \\
\hline & Descending colon & 33 & 18.8 & 46 & 23.5 & & \\
\hline & Transverse colon & 42 & 23.9 & 45 & 23 & & \\
\hline & Rectum & 24 & 13.6 & 19 & 9.7 & & \\
\hline & Cecum & 11 & 6.3 & 19 & 9.7 & & \\
\hline & Sigmoid & 33 & 18.8 & 26 & 13.3 & & \\
\hline \multirow{5}{*}{$\begin{array}{c}\text { Size of polyps, } \\
\text { mm }\end{array}$} & Less than 5 & 80 & 45.5 & 98 & 50 & \multirow{5}{*}{ Chi-Square } & \multirow{5}{*}{0.37} \\
\hline & $6-10$ & 56 & 31.8 & 66 & 33.7 & & \\
\hline & $11-20$ & 28 & 15.9 & 25 & 12.8 & & \\
\hline & $21-50$ & 10 & 5.7 & 7 & 3.6 & & \\
\hline & More than 50 & 2 & 1.1 & 0 & 0 & & \\
\hline \multirow{8}{*}{ Histology of polyps } & Epithelial (adenomatous) & 128 & 72.7 & 172 & 78.8 & \multirow{8}{*}{ Chi-Square } & \multirow{8}{*}{0.009} \\
\hline & Epithelial (hyperplastic) & 23 & 13.1 & 13 & 5.6 & & \\
\hline & Hamartoma (Peutz Jeghers) & 4 & 2.3 & 0 & 0 & & \\
\hline & Epithelial (juvenile) & 5 & 2.8 & 1 & 0.5 & & \\
\hline & Epithelial (mixed) & 0 & 0 & 1 & 0.5 & & \\
\hline & Inflammatory (IBD) & 9 & 5.1 & 4 & 2 & & \\
\hline & Inflammatory (unknown) & 6 & 3.4 & 5 & 2.6 & & \\
\hline & Vascular (mesenchymal) & 1 & 0.6 & 0 & 0 & & \\
\hline \multirow{2}{*}{ Morphology of polyp } & Sessile & 162 & 92.6 & 182 & 2.9 & \multirow{2}{*}{ Chi-Square } & \multirow{2}{*}{0.91} \\
\hline & Pedunculate & 13 & 7.4 & 14 & 7.1 & & \\
\hline
\end{tabular}


Table 3. Histologic and morphologic details of polyps based on location

\begin{tabular}{|c|c|c|c|c|c|c|c|c|c|c|c|c|c|}
\hline \multirow[t]{2}{*}{ Variable } & & \multicolumn{2}{|c|}{$\begin{array}{l}\text { Ascending colon } \\
\qquad(n=74)\end{array}$} & \multicolumn{2}{|c|}{$\begin{array}{c}\text { Descending } \\
\text { colon }(n=79)\end{array}$} & \multicolumn{2}{|c|}{$\begin{array}{c}\text { Transverse } \\
\text { colon }(n=87)\end{array}$} & \multicolumn{2}{|c|}{ Rectum $(n=43)$} & \multicolumn{2}{|c|}{ Cecum $(n=30)$} & \multicolumn{2}{|c|}{ Sigmoid $(n=59)$} \\
\hline & & No. & $\%$ & No. & $\%$ & No. & $\%$ & No. & $\%$ & No. & $\%$ & No. & $\%$ \\
\hline \multirow{2}{*}{ Gender } & Female & 28 & 37.8 & 29 & 36.7 & 31 & 35.6 & 16 & 37.2 & 10 & 33.3 & 26 & 44.1 \\
\hline & Male & 46 & 62.2 & 50 & 63.3 & 56 & 64.4 & 27 & 62.8 & 20 & 66.7 & 33 & 55.9 \\
\hline \multirow{5}{*}{$\begin{array}{l}\text { Size of } \\
\text { polyps, mm }\end{array}$} & Less than 5 & 31 & 41.9 & 29 & 36.7 & 47 & 54 & 29 & 67.4 & 16 & 53.3 & 26 & 44.1 \\
\hline & $6-10$ & 26 & 35.1 & 29 & 36.7 & 24 & 27.6 & 13 & 30.2 & 10 & 3.3 & 20 & 33.9 \\
\hline & $11-20$ & 10 & 31.5 & 16 & 20.3 & 14 & 16.1 & 1 & 2.3 & 2 & 6.7 & 10 & 16.9 \\
\hline & $21-50$ & 6 & 8.1 & 5 & 6.3 & 1 & 1.1 & 0 & 0 & 2 & 6.7 & 3 & 5.1 \\
\hline & More than 50 & 1 & 1.4 & 0 & 0 & 1 & 1.1 & 0 & 0 & 0 & 0 & 0 & 0 \\
\hline \multirow{8}{*}{$\begin{array}{l}\text { Histology of } \\
\text { polyps }\end{array}$} & Epithelial (adenomatous) & 57 & 77 & 68 & 8.1 & 70 & 80.5 & 32 & 74.4 & 25 & 83.3 & 48 & 81.4 \\
\hline & Epithelial (hyperplastic) & 9 & 12.2 & 7 & 8.9 & 8 & 9.2 & 7 & 16.3 & 3 & 10 & 2 & 3.4 \\
\hline & Hamartoma (Peutz-Jeghers) & 1 & 1.4 & 0 & 0 & 3 & 3.4 & 0 & 0 & 0 & 0 & 0 & 0 \\
\hline & Hamartoma (juvenile) & 3 & 4.1 & 1 & 1.3 & 0 & 0 & 0 & 0 & 0 & 0 & 2 & 3.4 \\
\hline & Epithelial (mixed) & 0 & 0 & 0 & 0 & 0 & 0 & 1 & 2.3 & 0 & 0 & 0 & 0 \\
\hline & Inflammatory (IBD) & 2 & 2.7 & 1 & 1.3 & 3 & 3.4 & 3 & 7 & 2 & 6.7 & 2 & 3.4 \\
\hline & Inflammatory (unknown) & 2 & 2.7 & 1 & 1.3 & 2 & 2.3 & 0 & 0 & 0 & 0 & 5 & 8.5 \\
\hline & Vascular (mesenchymal) & 0 & 0 & 0 & 0 & 1 & 1.1 & 0 & 0 & 0 & 0 & 0 & 0 \\
\hline \multirow{2}{*}{$\begin{array}{l}\text { Morphology } \\
\text { of polyp }\end{array}$} & Sessile & 67 & 90.5 & 71 & 89.9 & 79 & 90.7 & 0 & 0 & 29 & 96.7 & 56 & 94.9 \\
\hline & Pedunculate & 7 & 9.5 & 8 & 10.1 & 8 & 9.3 & 43 & 100 & 1 & 3.3 & 3 & 5.1 \\
\hline \multirow{2}{*}{ Age (years) } & Less than 58 & 33 & 44.6 & 33 & 41.8 & 42 & 48.3 & 24 & 55.8 & 11 & 36.7 & 33 & 55.9 \\
\hline & More than 58 & 41 & 55.4 & 46 & 58.2 & 45 & 51.7 & 19 & 44.2 & 19 & 63.3 & 26 & 44.1 \\
\hline
\end{tabular}

biopsy samples is an important and effective method for diagnosing the types of polyps in the large intestine (17). These data are in line with the findings of our study. In another study by Masood and Rajpoot which was performed in 2007 in the United Kingdom, classification of colon biopsy samples was evaluated. In this study, the authors reported that there were no significant differences between results of biopsies regarding histology of polyps among men and women (18). These results were in line with our results.

Our data also showed that low grade adenomatous polyps in the transverse colon were most frequent among biopsies. In another study by Zare-Mirzaie et al, 211 biopsies in the large intestine were evaluated. They showed that no significant differences were observed among males and females and $16.2 \%$ of polyps had high grade dysplasia and also showed that adenomatous polyps were most frequent (20). These results are in line with our findings. In another study by Teriaky and colleagues in 2012 in Canada, sessile serrated adenomas of 33 patients were reviewed and evaluated. They showed that these polyps occurred more frequently in females and in the

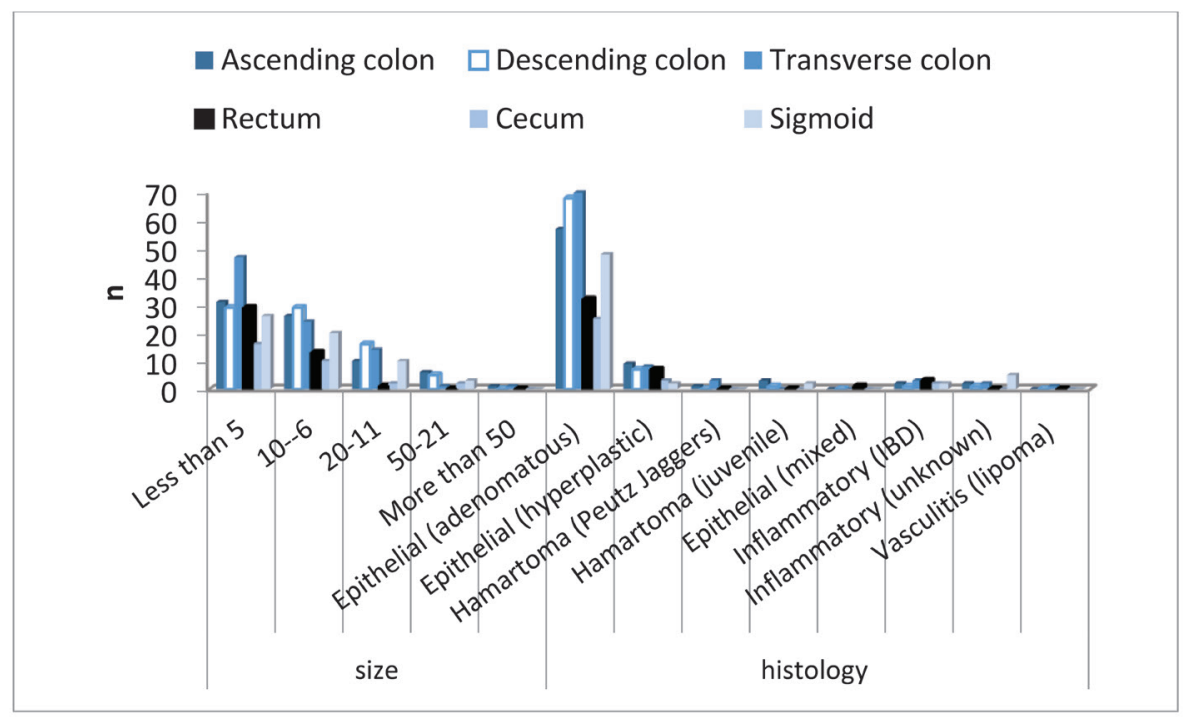

Figure 1. Size and histology of polyps based on their location. 


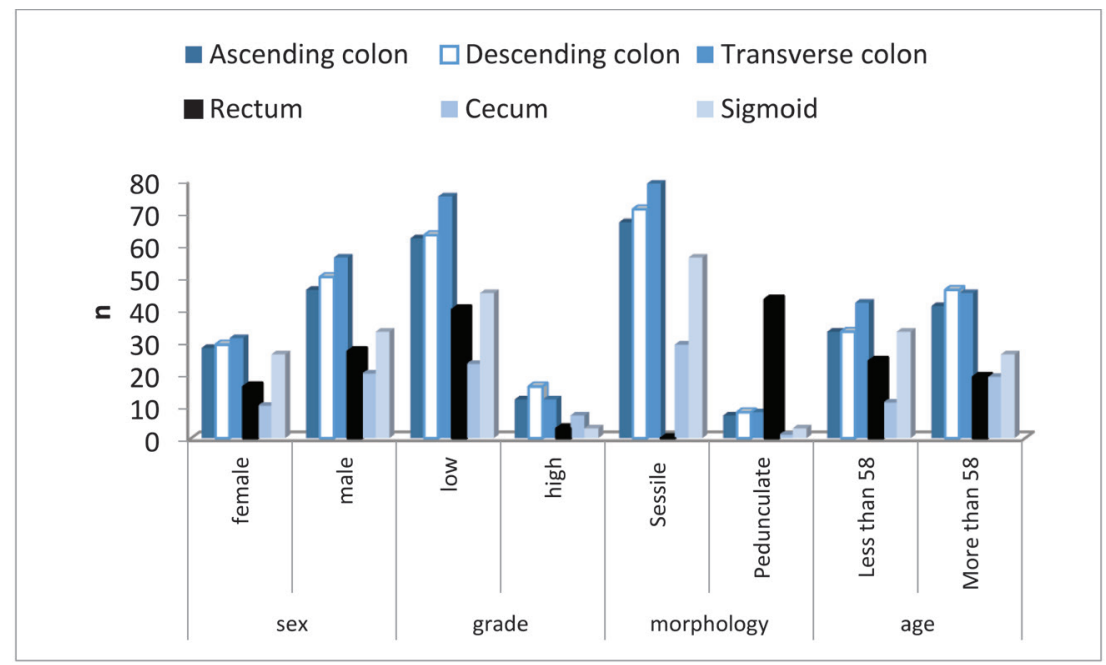

Figure 2. Other classifications of polyps based on their location

right colon (21). Yang et al also evaluated biopsies of 11201 patients in 2015. They indicated that adenomatous polyps are mostly observed in the cecum and ascending colon, whereas there is low prevalence in both the transverse and distal colon (22). These results are not in line with our findings. We indicated higher prevalence of adenomatous polyps in transverse colon compared with other locations. These differences could be due to the investigated study populations.

Showing higher frequencies of adenomatous epithelial polyps in both age groups in our study and also the higher frequencies of such polyps in transverse colon emphasized the importance of this issue. We also suggest that physicians and colonoscopists should pay more attention to this issue. We also believe that more studies might be required in this regard.

\section{Conclusion}

Here in the current study we showed that no significant differences between two genders regarding location, size, histology and morphology of polyps. We also showed that adenomatous epithelial polyps are more frequent in patients and most of the discovered polyps were in transverse colon and most of them were adenomatous epithelial and also low grade. These data were in line with most of previous studies. However, some paradoxical results were reported. Taken together, we believe that more studies on larger populations should be performed.

\section{Limitations of the study}

The most important limitation of the current study was the documents and limited study population. We also suggest that more studies with longer follow up period should be performed.

Authors' contribution

PMZ and SG and MD were the principal investigators of the study. PMZ and SG, and MD were included in preparing the concept and design. PMZ and SG and MD were revised the manuscript and critically evaluated the intellectual contents. All authors have read and approved the content of the manuscript and confirmed the accuracy or integrity of any part of the work.

Conflicts of interest

The authors declare that they have no competing interests.

Ethical considerations

Ethical issues (including plagiarism, data fabrication, double publication) have been completely observed by the authors.

Funding/support

This study was supported by Isfahan University of Medical Sciences (Grant \#398557).

References

1. Zanghì G, Leanza V, Vecchio R, D'Agati A, Cordova S, Rinzivillo NM, et al. Neoplastic sigmoid-uterine fistula. An exceptional complication of large intestine cancer. II Giornale di chirurgia. 2017;38(1):37-40. doi: 10.11138/gchir/2017.38.1.037

2. Barsouk A, Rawla P, Barsouk A, Thandra KC. Epidemiology of cancers of the small intestine: trends, risk factors, and prevention. Med Sci (Basel). 2019;7:46. doi: 10.3390/ medsci7030046.

3. Rawla P, Sunkara T, Barsouk A. Epidemiology of colorectal cancer: incidence, mortality, survival, and risk factors. Prz Gastroenterol. 2019;14:89-103. doi: 10.5114/pg.2018.81072.

4. Marley AR, Nan H. Epidemiology of colorectal cancer. Int J Mol Epidemiol Genet. 2016;7:105-114.

5. Murphy N, Jenab M, Gunter MJ. Adiposity and gastrointestinal cancers: epidemiology, mechanisms and future directions. Nat Rev Gastroenterol Hepatol. 2018;15:659-670. doi: 10.1038/ s41575-018-0038-1.

6. Rawla P, Barsouk A. Epidemiology of gastric cancer: global trends, risk factors and prevention. Prz Gastroenterol. 2019;14:26-38. doi: 10.5114/pg.2018.80001.

7. Wu S, Powers S, Zhu W, Hannun YA. Substantial contribution of extrinsic risk factors to cancer development. Nature. 2016;529:43-7. doi: 10.1038/nature16166.

8. Zhang M, Yang D, Gold B. The adenomatous polyposis coli (APC) mutation spectra in different anatomical regions of the large intestine in colorectal cancer. Mutat Res. 2018;810:1-5. doi: 10.1016/j.mrfmmm.2018.04.003. 
9. Snover DC. Diagnostic and reporting issues of preneoplastic polyps of the large intestine with early carcinoma. Ann Diagn Pathol. 2019;39:1-14. doi: 10.1016/j. anndiagpath.2018.11.001.

10. Pai RK, Bettington M, Srivastava A, Rosty C. An update on the morphology and molecular pathology of serrated colorectal polyps and associated carcinomas. Mod Pathol. 2019;32:13901415. doi: 10.1038/s41379-019-0280-2.

11. Ponugoti PL, Cummings OW, Rex DK. Risk of cancer in small and diminutive colorectal polyps. Dig Liver Dis. 2017;49:3437. doi: 10.1016/j.dld.2016.06.025.

12. Bettington M, Walker N, Rosty C, Brown I, Clouston A, McKeone D, et al. Serrated tubulovillous adenoma of the large intestine. Histopathology. 2016;68:578-87. doi: 10.1111/ his. 12788.

13. Siegel R, Desantis C, Jemal A. Colorectal cancer statistics, 2014. CA Cancer J Clin. 2014;64:104-17. doi: 10.3322/ caac. 21220 .

14. Patel SG, Ahnen DJ. Colorectal Cancer in the Young. Curr Gastroenterol Rep. 2018;20:15. doi: 10.1007/s11894-0180618-9.

15. Markowitz SD, Bertagnolli MM. Molecular origins of cancer: Molecular basis of colorectal cancer. $N$ Engl J Med. 2009;361(25):2449-60. doi: 10.1056/NEJMra0804588.

16. Mehta V, Desai D, Abraham P, Gupta T, Rodrigues C, Joshi A, et al. Do additional colonoscopic biopsies increase the yield of Mycobacterium tuberculosis culture in suspected ileo-colonic tuberculosis? Indian J Gastroenterol. 2018;37:226-30. doi: 10.1007/s12664-018-0863-8.

17. Galamb O, Györffy B, Sipos F, Spisák S, Németh AM, Miheller $\mathrm{P}$, et al. Inflammation, adenoma and cancer: objective classification of colon biopsy specimens with gene expression signature. Disease Markers. 2008;25(1):1-16. doi: 10.1155/2008/586721.

18. Masood K, Rajpoot N, Nasir M. Classification of colon biopsy samples by spatial analysis of a single spectral band from its hyperspectral cube. In: 11th Medical Image Understanding and Analysis (MIUA 2007); 17-18 Jul 2007; Aberystwyth, Wales.

19. Rampertab SD, Pooran N, Brar P, Singh P, Green PH. Trends in the presentation of celiac disease. Am J Med. 2006;119(4):355. e9-14. doi: 10.1016/j.amjmed.2005.08.044.

20. Zare-Mirzaie A, Abolhasani M, Aryamanesh A. Left sided colorectal adenomatous polyps have more risk for high grade dysplasia. Acta Med Iran. 2013;51(3):172-7.

21. Teriaky A, Driman DK, Chande N. Outcomes of a 5-year follow-up of patients with sessile serrated adenomas. Scand J Gastroenterol. 2012;47:178-83. doi: 10.3109/00365521.2011.645499.

22. Yang JF, Tang SJ, Lash RH, Wu R, Yang Q. Anatomic distribution of sessile serrated adenoma/polyp with and without cytologic dysplasia. Arch Pathol Lab Med. 2015;139:388-93. doi: 10.5858/arpa.2013-0523-OA. 